\title{
ANÁLISE REGIONAL DE VAZÃo MÍNIMA DE REFERÊNCIA NA REGIÃo CENTRO-SUL DO ESTADO DO ESPÍRITO SANTO
}

\author{
REFERENCE MINIMUM FLOWS REGIONALIZATION FOR THE CENTRAL-SOUTH \\ PORTION OF ESPÍRITO SANTO STATE
}

\author{
José Antônio Tosta dos Reis ${ }^{1}$, Marco Aurélio Costa Caiado ${ }^{2}$, Jéssica Ferreira Barbosa ${ }^{3}$, Michelli Moscon ${ }^{4}$, \\ Antônio Sérgio Ferreira Mendonça ${ }^{5}$ \\ ${ }^{1}$ Professor do Programa de Pós-Graduação em Engenharia Ambiental da Universidade Federal do Espírito Santo. \\ Departamento de Engenharia Ambiental. Av. Fernando Ferrari, 514, Goiabeiras, Vitória, ES. CEP: 29.075-910. \\ E-mail: tosta@ct.ufes.br. \\ ${ }^{2}$ Professor da Coordenadoria de Saneamento Ambiental do Instituto Federal do Espírito Santo. Avenida Vitória, 1729, \\ Jucutuquara, Vitória, ES. CEP: 29.040-780. E-mail: mcaiado@ifes.edu.br. \\ ${ }^{3}$ Tecnóloga em Saneamento Ambiental pelo Instituto Federal do Espírito Santo. Avenida Vitória, 1729, Jucutuquara, \\ Vitória, ES. CEP: 29.040-780. E-mail: je.fbarbosa@ hotmail.com. \\ ${ }^{4}$ Tecnóloga em Saneamento Ambiental pelo Instituto Federal do Espírito Santo. Avenida Vitória, 1729, Jucutuquara, \\ Vitória, ES. CEP: 29.040-780. E-mail: michelimoscon@hotmail.com. \\ ${ }^{5}$ Professor do Programa de Pós-Graduação em Engenharia Ambiental da Universidade Federal do Espírito Santo. \\ Departamento de Engenharia Ambiental. Av. Fernando Ferrari, 514, Goiabeiras, Vitória, ES. CEP: 29.075-910. \\ E-mail: anserfm@terra.com.br.
}

\begin{abstract}
RESUMO
A regionalização hidrológica é uma técnica utilizada para transferir espacialmente informações, buscando explorar ao máximo os dados disponíveis numa determinada região. Este trabalho estabeleceu funções regionais aplicáveis à apropriação da vazão mínima com permanência de $90 \%$ (vazão mínima de referência para a condução do processo de outorga pelo uso da água) na porção Centro-Sul do estado do Espírito Santo, região que envolve as bacias hidrográficas dos rios Jucu, Benevente, Novo, Iconha e Itapemirim. Em razão da ampliação do parque industrial siderúrgico instalado, da implantação de plantas industriais e porto associados à exploração de petróleo e gás, a região estudada tem a perspectiva de receber consideráveis investimentos em infraestrutura e de experimentar substancial crescimento populacional. Esse crescimento, se estabelecido, demandará volumes cada vez maiores de água, pressionando os recursos hídricos superficiais da região. O presente trabalho identificou duas regiões hidrologicamente homogêneas na área de estudo e estabeleceu funções regionais que permitiram estimar valores da vazão mínima de referência com erros sistematicamente inferiores a $15 \%$.
\end{abstract}

Palavras-chave: Regionalização de vazões. Vazão mínima. Outorga.

\begin{abstract}
There were established regional equations for estimates of $\mathrm{Q}_{90}$, minimum flow to remain $90 \%$ of the time, for the south-central portion of the Espirito Santo state, Brazil. The Q90 is utilized as reference for water use permits analysis in Espírito Santo. Due to the perspective of steel, oil and gas industries expansion, it is expected substantial population and industries water demands growth in the region. There were employed Geographical Information System and multiple regression analysis by the Best Subsets approach. The independent variables considered were area, perimeter, drainage density, total length of watercourses and average altitude, slope and precipitation. The study identified two hydrologically homogeneous areas in the study region and adjusted functions that allow estimates of values for the $\mathrm{Q}_{90}$ reference minimum flow presenting error magnitudes below $15 \%$.
\end{abstract}

Keywords: Regionalization. Minimum flow. Water use permits. 


\section{INTRODUÇÃO}

A regionalização hidrológica apresenta-se como uma técnica por meio da qual é possível a transferência de informações dentro de uma área com comportamento hidrológico uniforme. Sua utilização tem se difundido como alternativa para auxiliar na descrição de diferentes fases do ciclo hidrológico em diferentes regiões do mundo, principalmente em locais nos quais o monitoramento hidrometeorológico apresenta alguma deficiência. Os trabalhos de Wiltshire (1985), Seibert (1999), Funke (1999), Dinpashoha et al. (2004), Timilsena e Piechota (2008), Santhi et al. (2008) e González e Valdéz (2008) constituem exemplos de diferentes formas de aplicação da técnica de regionalização hidrológica.

No Brasil, em virtude das deficiências da rede hidrométrica em funcionamento, a regionalização hidrológica tem sido recorrentemente empregada para a avaliação do comportamento do regime de vazões em diferentes bacias hidrográficas (Obregon et al., 1999; Euclydes et al., 2001; Baena, 2002; Elesbon, 2004).

No estado do Espírito Santo, diferentes trabalhos propuseram funções regionais aplicáveis à avaliação de vazões mínimas. Dentre esses trabalhos, há o de Coser (2003), que estabeleceu funções regionais aplicáveis à apropriação da vazão mínima de sete dias associada ao período de retorno de dez anos $\left(\mathrm{Q}_{7,10}\right)$, vazão de referência utilizada para regular a outorga do uso da água até o ano de 2009. Nas referidas funções regionais, a área de drenagem e a precipitação média de longo período figuraram como variáveis independentes. O estudo sugeriu três regiões hidrologicamente homogêneas, não tendo sido estabelecidas funções regionais para a porção capixaba da bacia hidrográfica do Rio Doce.

Reis et al. (2006), por sua vez, sugeriram funções regionais para a reconstrução da curva de permanência de vazão entre as permanências de $50 \%$ e $95 \%$. A proposta de regionalização envolveu a definição de curvas de permanência para 27 estações fluviométricas instaladas e em funcionamento no estado. Para a área e a precipitação média anual da bacia hidrográfica de cada estação fluviométrica foram consideradas as variáveis independentes da regionalização. O trabalho permitiu identificar três regiões hidrologicamente homogêneas e, assim como o trabalho proposto por Coser (2003), não definiu funções regionais aplicáveis à porção capixaba do Rio Doce.

O trabalho proposto por Reis et al. (2008) estabeleceu indicadores regionais aplicáveis à avaliação de vazões máximas, médias e mínimas na bacia hidrográfica do Rio Itabapoana, rio de domínio federal que, em boa parte da sua extensão, define a divisa entre os estados do Rio de Janeiro e do Espírito Santo. Os indicadores propostos estabelecidos para a apropriação das vazões mínimas apresentaram erros significativos quando da confrontação dos valores reais e dos valores estimados de vazão, em muitas situações superando a marca de $40 \%$. Adicionalmente, os autores observaram que os maiores erros foram registrados nas bacias com menores áreas de drenagem. Dessa forma, Reis et al. (2008) não recomendaram a aplicação dos indicadores para avaliação das vazões de estiagem em pequenas bacias hidrográficas e nas proximidades daquelas estações fluviométricas nas quais os erros percentuais produzidos com a aplicação dos indicadores regionais foram mais expressivos.

No estado do Espírito Santo, com a publicação da Instrução Normativa $n^{0} 13$ do Instituto Estadual de Meio Ambiente e Recursos Hídricos, editada em 9 de dezembro de 2009, a vazão mínima com permanência de $90 \%\left(\mathrm{Q}_{90}\right)$ passou a constituir a vazão de referência para o processo de outorga do uso da água.

A regionalização da vazão $Q_{90}$ para a porção Centro-Sul do estado do Espírito Santo - região com forte vocação siderúrgica e com a perspectiva de receber plantas industriais e porto associados à exploração de petróleo e gás - constitui o principal objetivo deste trabalho. 


\section{MATERIAL E MÉTODOS}

\section{1. Área de estudo}

O presente estudo envolve as bacias hidrográficas dos rios Jucu, Benevente, Novo, Iconha e Itapemirim, rios de domínio estadual localizados na porção Centro-Sul do estado do Espírito Santo.

A bacia do rio Benevente é caracterizada por abrigar importante polo siderúrgico do estado. A estrutura local envolve indústria de pelotização abastecida por mineroduto para transporte de minério de ferro (maior mineroduto do mundo, com extensão de $396 \mathrm{~km}$ ) e porto para exportação de pelotas de minério. Nos próximos anos, a bacia abrigará uma nova siderúrgica e plantas industriais associadas à exploração de petróleo e gás, atividades em franca expansão no estado.

As bacias dos rios Novo e Iconha não apresentam vocação industrial, abrigando predominantemente atividades agropecuárias, comércio e serviço. No ramo da exploração mineral, a bacia do Rio Itapemirim constitui importante polo de produção de mármore e granito, produtos explorados e beneficiados principalmente no município de Cachoeiro de Itapemirim, maior produtor nacional de mármores. Pela sua extensão territorial e por abrigar importantes municípios do Sul do estado do Espírito Santo, a bacia do Rio Itapemirim também acolhe diversos polos de comércio e serviço, além de diversificado grupo de atividades ligadas à agricultura e à pecuária.

A bacia do Rio Jucu, localizada na porção Central do estado, é um dos principais mananciais responsáveis pelo abastecimento público da região Metropolitana da Grande Vitória (RMGV), região que abriga a capital capixaba e os municípios de Vila Velha, Cariacica, Serra, Viana, Fundão e Guarapari. A RMGV abriga, aproximadamente, metade da população total do Espírito Santo $46 \%$ e $57 \%$ da população urbana do estado, além de produzir $58 \%$ da riqueza e consumir $55 \%$ da energia elétrica.

\subsection{Informações hidrometeorológicas}

Para o estabelecimento das funções regionais, foram selecionados registros constituídos de vazões médias diárias de estações fluviométricas instaladas e em operação nas bacias dos rios Jucu, Benevente, Novo, Iconha e Itapemirim. Todas as informações fluviométricas, objeto de análise, foram obtidas a partir do sítio oficial da Agência Nacional de Águas (ANA) e manipuladas com auxílio do programa computacional HIDRO®, programa de domínio público produzido e disponibilizado pela ANA. A relação das estações fluviométricas selecionadas é apresentada pela Tabela 1. Para cada estação fluviométrica, são apresentadas as coordenadas geográficas, altitude, curso d'água e município nos quais estão instaladas. A Figura 1, por sua vez, ilustra a distribuição espacial das referidas estações fluviométricas. 
Tabela 1: Estações fluviométricas selecionadas para análise regional da vazão mínima de referência

\begin{tabular}{|c|c|c|c|c|c|}
\hline Nome & Curso d'água & Municípios & Latitude & Longitude & Altitude (m) \\
\hline Córrego do Galo & Rio Jucu - Braço Norte & Domingos Martins & $20^{\circ} 18^{\prime} 59^{\prime \prime}$ & $40^{\circ} 39^{\prime} 06^{\prime \prime}$ & 425 \\
\hline Fazenda Jucuruaba & Rio Jucu & Viana & $20^{\circ} 24^{\prime} 54^{\prime \prime}$ & $40^{\circ} 29^{\prime} 07^{\prime \prime}$ & 40 \\
\hline Matilde & Rio Benevente & Alfredo Chaves & $20^{\circ} 33^{\prime} 24^{\prime \prime}$ & $40^{\circ} 48^{\prime} 41^{\prime \prime}$ & 525 \\
\hline Pau D'alho & Rio Novo & Rio Novo do Sul & 205'11'” & $40^{\circ} 56^{\prime} 47^{\prime \prime}$ & 15 \\
\hline Iconha-Montante & Rio Iconha & Iconha & $20^{\circ} 47^{\prime} 01^{\prime \prime}$ & $40^{\circ} 49^{\prime} 33^{\prime \prime}$ & 25 \\
\hline Usina Fortaleza & Rio Braço Norte Esquerdo & Muniz Freire & $20^{\circ} 22^{\prime} 7^{\prime \prime}$ & $41^{\circ} 24^{\prime} 32^{\prime \prime}$ & 554 \\
\hline Iuna & Rio Pardo & Iuna & $20^{\circ} 21^{\prime} 08^{\prime \prime}$ & $41^{\circ} 31^{\prime} 58^{\prime \prime}$ & 640 \\
\hline Terra Corrida - Montante & Rio Pardo & Muniz Freire & $20^{\circ} 25^{\prime} 49^{\prime \prime}$ & $41^{\circ} 30^{\prime} 10^{\prime \prime}$ & 380 \\
\hline Itaici & Rio Braço Norte Esquerdo & Muniz Freire & $20^{\circ} 31^{\prime} 42^{\prime \prime}$ & $41^{\circ} 30^{\prime} 41^{\prime \prime}$ & 374 \\
\hline Ibitirama & Rio Braço Norte Direito & Alegre & $20^{\circ} 32^{\prime} 26^{\prime \prime}$ & $41^{\circ} 39^{\prime} 56^{\prime \prime}$ & 710 \\
\hline Rive & Rio Itapemirim & Alegre & $20^{\circ} 44^{\prime} 49^{\prime \prime}$ & $41^{\circ} 27^{\prime} 58^{\prime \prime}$ & 128 \\
\hline Castelo & Rio Castelo & Castelo & $20^{\circ} 36^{\prime} 22^{\prime \prime}$ & $41^{\circ} 11^{\prime} 59^{\prime \prime}$ & 107 \\
\hline Usina São Miguel & Rio Castelo & Cachoeiro do Itapemirim & $20^{\circ} 42^{\prime} 09^{\prime \prime}$ & $41^{\circ} 10^{\prime} 25^{\prime \prime}$ & 200 \\
\hline Coutinho & Rio Itapemirim & Cachoeiro do Itapemirim & $20^{\circ} 45^{\prime} 30^{\prime \prime}$ & $41^{\circ} 10^{\prime} 25^{\prime \prime}$ & 15 \\
\hline
\end{tabular}

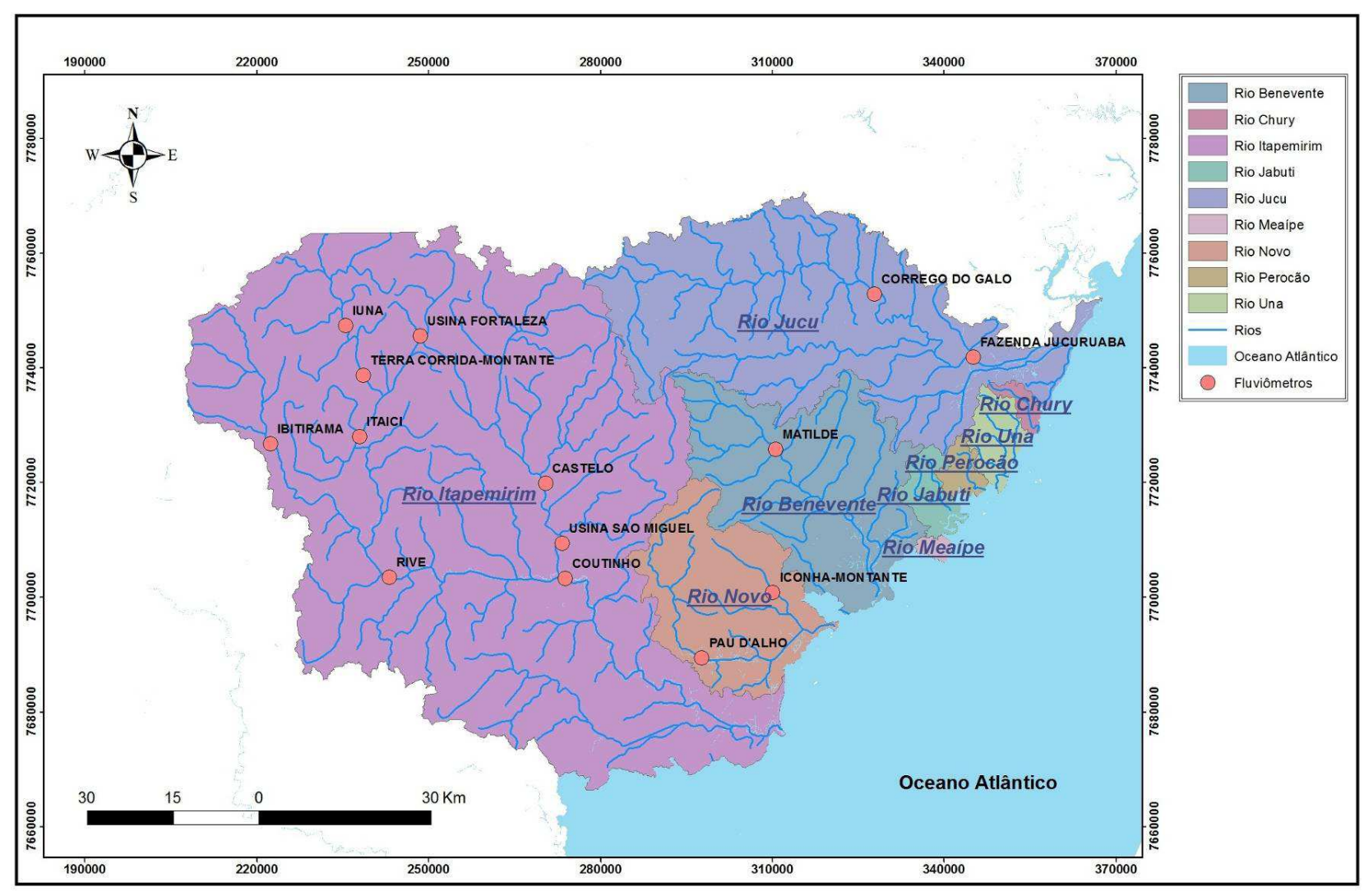

Figura 1: Distribuição espacial das estações instaladas nas bacias dos rios Jucu, Benevente, Novo, Iconha e Itapemirim

\subsection{Características fisiográficas e pluviometria}

A caracterização fisiográfica das bacias hidrográficas em estudo foi realizada com auxílio de Sistemas de Informações Geográficas. O programa ArcGis ${ }^{\circledR}$ foi utilizado para a obtenção do modelo 
digital do terreno, a partir do qual foi produzido o mapa de declividade e apropriados área de drenagem, perímetro, comprimento total dos cursos d'água, densidade de drenagem e declividade média das bacias hidrográficas dos postos fluviométricos estudados. Adicionalmente, o ArcGis permitiu a obtenção da precipitação média de longo período para cada bacia hidrográfica estudada. A relação das estações pluviométricas utilizadas para apropriação da precipitação média é apresentada pela Tabela 2 .

Tabela 2: Estações pluviométricas selecionadas para avaliação da precipitação média de longo período

\begin{tabular}{|c|c|c|c|c|c|}
\hline Nome & Município & $\mathbf{U F}$ & Latitude & Longitude & Altitude (m) \\
\hline Fazenda Jucuruaba & Viana & ES & $-20^{\circ} 24^{\prime} 54^{\prime \prime}$ & $-40^{\circ} 29^{\prime} 07^{\prime \prime}$ & 80 \\
\hline Guarapari (DNOS) & Guarapari & ES & $-20^{\circ} 39^{\prime} 08^{\prime \prime}$ & $-40^{\circ} 30^{\prime} 31^{\prime \prime}$ & 6 \\
\hline Iconha-Montante & Iconha & ES & $-20^{\circ} 47^{\prime} 01^{\prime \prime}$ & $-40^{\circ} 49^{\prime} 33^{\prime \prime}$ & 25 \\
\hline Usina Paineiras (DNOS) & Itapemirim & ES & $-20^{\circ} 57^{\prime} 10^{\prime \prime}$ & $-40^{\circ} 57^{\prime} 12^{\prime \prime}$ & 40 \\
\hline Garrafão (DNOS) & Santa Leopoldina & ES & $-20^{\circ} 08^{\prime} 36^{\prime \prime}$ & $-40^{\circ} 58^{\prime} 31^{\prime \prime}$ & 940 \\
\hline Anchieta (DNOS) & Anchieta & ES & $-20^{\circ} 48^{\prime} 13^{\prime \prime}$ & $-40^{\circ} 39^{\prime} 22^{\prime \prime}$ & 6 \\
\hline Matilde (DNOS) & Alfredo Chaves & ES & $-20^{\circ} 33^{\prime} 24^{\prime \prime}$ & $-40^{\circ} 48^{\prime} 41^{\prime \prime}$ & 515 \\
\hline Marechal Floriano (DNOS) & Domingos Martins & ES & $-20^{\circ} 24^{\prime} 43^{\prime \prime}$ & $-40^{\circ} 40^{\prime} 56^{\prime \prime}$ & 544 \\
\hline Rio Novo do Sul (DNOS) & Rio Novo do Sul & ES & $-20^{\circ} 52^{\prime \prime} 52^{\prime \prime}$ & $-40^{\circ} 56^{\prime} 36^{\prime \prime}$ & 80 \\
\hline Perobinha (DNOS) & Domingos Martins & ES & $-20^{\circ} 17^{\prime} 01^{\prime \prime}$ & $-40^{\circ} 46^{\prime} 59^{\prime \prime}$ & 640 \\
\hline Duas Barras (DNOS) & Iconha & ES & $-20^{\circ} 43^{\prime} 41^{\prime \prime}$ & $-40^{\circ} 52^{\prime} 57^{\prime \prime}$ & 0 \\
\hline Vila Nova Maravilha (DNOS) & Alfredo Chaves & ES & $-20^{\circ} 35^{\prime} 15^{\prime \prime}$ & $-40^{\circ} 56^{\prime} 57^{\prime \prime}$ & 100 \\
\hline São Rafael & Domingos Martins & ES & $-20^{\circ} 17^{\prime} 47^{\prime \prime}$ & $-40^{\circ} 56^{\prime} 02^{\prime \prime}$ & 818 \\
\hline Atílio Vivacqua & Atílio Vivacqua & ES & $-20^{\circ} 54^{\prime} 46^{\prime \prime}$ & $-41^{\circ} 11^{\prime} 42^{\prime \prime}$ & 76 \\
\hline Guaçuí & Guaçuí & ES & $-20^{\circ} 46^{\prime} 25^{\prime \prime}$ & $-41^{\circ} 40^{\prime} 54^{\prime \prime}$ & 576 \\
\hline Castelo & Castelo & ES & $-20^{\circ} 36^{\prime} 20^{\prime \prime}$ & $-41^{\circ} 11^{\prime} 59^{\prime \prime}$ & 107 \\
\hline Rive & Alegre & ES & $-20^{\circ} 44^{\prime} 49^{\prime \prime}$ & $-41^{\circ} 27^{\prime} 58^{\prime \prime}$ & 127 \\
\hline Caiana & Caiana & MG & $-20^{\circ} 41^{\prime} 38^{\prime \prime}$ & $-41^{\circ} 55^{\prime} 19^{\prime \prime}$ & 747 \\
\hline Jaciguá (DNOS) & Cachoeiro do Itapemirim & ES & $-20^{\circ} 42^{\prime} 07^{\prime \prime}$ & $-41^{\circ} 00^{\prime} 59^{\prime \prime}$ & 580 \\
\hline Conceição do Castelo (DNOS) & Conceição do Castelo & ES & $-20^{\circ} 21^{\prime} 08^{\prime \prime}$ & $-41^{\circ} 1422^{\prime \prime}$ & 600 \\
\hline Muniz Freire (DNOS) & Muniz Freire & ES & $-20^{\circ} 27^{\prime} 00^{\prime \prime}$ & $-41^{\circ} 24^{\prime} 00^{\prime \prime}$ & 0 \\
\hline Iuna & Iuna & ES & $-20^{\circ} 20^{\prime} 45^{\prime \prime}$ & $-41^{\circ} 32^{\prime} 15^{\prime \prime}$ & 615 \\
\hline Dores do Rio Preto & Dores do Rio Preto & ES & $-20^{\circ} 41^{\prime} 09^{\prime \prime}$ & $-41^{\circ} 50^{\prime} 46^{\prime \prime}$ & 772 \\
\hline Fazenda Monte Alegre (DNOS) & Muqui & ES & $-20^{\circ} 56^{\prime} 41^{\prime \prime}$ & $-41^{\circ} 24^{\prime} 03^{\prime \prime}$ & 600 \\
\hline Ibitirama (DNOS) & Alegre & ES & $-20^{\circ} 32^{\prime} 26^{\prime \prime}$ & $-41^{\circ} 39^{\prime} 56^{\prime \prime}$ & 794 \\
\hline Santa Cruz - Caparaó (DNOS) & Iuna & ES & $-20^{\circ} 19^{\prime} 22^{\prime \prime}$ & $-41^{\circ} 42^{\prime} 15^{\prime \prime}$ & 920 \\
\hline Usina Fortaleza (DNOS) & Muniz Freire & ES & $-20^{\circ} 22^{\prime} 17^{\prime \prime}$ & $-41^{\circ} 24^{\prime} 32^{\prime \prime}$ & 580 \\
\hline Itaici & Muniz Freire & ES & $-20^{\circ} 31^{\prime} 42^{\prime \prime}$ & $-41^{\circ} 30^{\prime} 41^{\prime \prime}$ & 380 \\
\hline Arace (DNOS) & Domingos Martins & ES & $-20^{\circ} 22^{\prime} 00^{\prime \prime}$ & $-41^{\circ} 03^{\prime} 40^{\prime \prime}$ & 1075 \\
\hline Burarama (DNOS) & Cachoeiro do Itapemirim & ES & $-20^{\circ} 40^{\prime} 50^{\prime \prime}$ & $-41^{\circ} 20^{\prime} 54^{\prime \prime}$ & 180 \\
\hline Varre-Sai & Natividade & RJ & $-20^{\circ} 55^{\prime} 51^{\prime \prime}$ & $-41^{\circ} 51^{\prime} 00^{\prime \prime}$ & 650 \\
\hline Porciuncula & Porciuncula & RJ & $-20^{\circ} 5748^{\prime \prime}$ & $-42^{\circ} 0214^{\prime \prime}$ & 278 \\
\hline Barra do Itapemirim (DNOS) & Itapemirim & ES & $-21^{\circ} 00^{\prime} 27^{\prime \prime}$ & $-40^{\circ} 50^{\prime} 07^{\prime \prime}$ & 4 \\
\hline Ponte de Itabapoana & Mimoso do Sul & ES & $-21^{\circ} 12^{\prime} 22^{\prime \prime}$ & $-41^{\circ} 27^{\prime} 46^{\prime \prime}$ & 59 \\
\hline Mimoso do Sul (DNOS) & Mimoso do Sul & ES & $-21^{\circ} 03^{\prime} 53^{\prime \prime}$ & $-41^{\circ} 21^{\prime} 45^{\prime \prime}$ & 67 \\
\hline São José do Calçado & São José do Calçado & ES & $-21^{\circ} 02^{\prime} 12^{\prime \prime}$ & $-41^{\circ} 39^{\prime} 08^{\prime \prime}$ & 150 \\
\hline São José das Torres & Mimoso do Sul & ES & $-21^{\circ} 03^{\prime} 45^{\prime \prime}$ & $-41^{\circ} 14^{\prime} 28^{\prime \prime}$ & 120 \\
\hline
\end{tabular}




\subsection{Curvas de permanência e vazões $Q_{90}$}

A curva de permanência indica a porcentagem de tempo que um determinado valor de vazão foi igualado ao ultrapassado durante o período de observação. Tucci (2002) sistematiza os procedimentos necessários à construção de uma curva de permanência.

Neste estudo, as curvas de permanência foram construídas a partir do programa computacional HIDRO® (ANA, 2002). Para a obtenção das curvas de permanência, foram utilizadas as vazões médias diárias registradas entre os anos de 1969 e 2008. Estabelecidas as curvas de permanência, as vazões $\mathrm{Q}_{90}$ - objeto deste estudo de regionalização - foram selecionadas.

\subsection{Funções regionais}

Para a determinação das funções regionais, foi empregada a análise de regressão simples e múltipla. Foram avaliadas as respostas de modelos potenciais nos quais as diferentes características fisiográficas e a precipitação média de longo período figuraram como variáveis independentes. Na análise de regressão simples, apenas a área de drenagem das bacias hidrográficas dos postos fluviométricos estudados figurou como variável independente. $\mathrm{Na}$ análise de regressão múltipla, figuraram como variáveis independentes a área de drenagem, perímetro, comprimento total de cursos d'água, densidade de drenagem, altitude média, declividade média e precipitação média de longo período de cada bacia hidrográfica.

Para os modelos produzidos a partir da análise de regressão múltipla, a abordagem dos melhores subconjuntos (Levine et al., 2005) foi empregada para a seleção das combinações de variáveis independentes que apresentaram as melhores respostas. Essa abordagem avalia todos os possíveis modelos de regressão ou os melhores subconjuntos para um determinado conjunto de variáveis independentes, utilizando-se dois diferentes critérios para a seleção dos modelos concorrentes:

- o coeficiente de correlação ajustado $\left(\mathrm{r}^{2}\right.$ ajustado), valor derivado do coeficiente de correlação a partir de ajustes introduzidos em função do tamanho da amostra e do número de variáveis independentes;

- o coeficiente $\mathrm{C}_{\mathrm{p}}$, detalhadamente apresentado e discutido por Levine et al. (2005), apropriado a partir da Equação 1.

$$
C_{p}=\frac{\left(1-r_{k}^{2}\right) \cdot(n-T)}{\left(1-r_{T}^{2}\right)}-(n-2 \cdot(k+1))
$$

$\mathrm{Na}$ expressão anterior, $\mathrm{k}$ representa o número de variáveis independentes em um modelo de regressão; T, o número total de parâmetros (incluindo a interseção) a serem estimados pelo modelo de regressão, o coeficiente de determinação múltipla para um modelo de regressão que possua k variáveis independentes e o coeficiente de determinação múltipla para um modelo de regressão completo que contenha todos os T parâmetros estimados. Segundo Levine et al. (2005), quando um modelo de regressão com $\mathrm{k}$ variáveis independentes contém somente diferenças aleatórias em relação a um modelo ideal, o valor médio de $\mathrm{Cp}$ é $\mathrm{k}+1$, o número de parâmetros. Dessa forma, dentro de um universo de modelos gerados a partir da análise de regressão múltipla, o objetivo é encontrar modelos cujo valor de $\mathrm{Cp}$ seja igual ou inferior a $\mathrm{k}+1$. Para a realização da análise de regressão, foi empregada a planilha eletrônica Microsoft Excel®.

\section{RESULTADOS E DISCUSSÕES}

A Tabela 3 apresenta as vazões $Q_{90}$, as características fisiográficas e a precipitação média de longo período associadas à bacia hidrográfica de cada estação fluviométrica estudada. 
Tabela 3: Vazão mínima de referência, características fisiográficas e precipitação média de longo período para as bacias hidrográficas das estações fluviométricas estudadas

\begin{tabular}{|c|c|c|c|c|c|c|c|}
\hline Estação & $\begin{array}{c}\text { Vazão } \mathbf{Q}_{\mathbf{9}} \mathbf{0} \\
\left(\mathbf{m}^{\mathbf{3}}\right)\end{array}$ & $\begin{array}{c}\text { Área } \\
\left(\mathbf{k m}^{2}\right)\end{array}$ & $\begin{array}{c}\text { Perímetro } \\
(\mathbf{k m})\end{array}$ & $\begin{array}{c}\text { Comprimento total } \\
\mathbf{d e ~ c u r s o s ~ d ' a ́ g u a ~} \\
(\mathbf{k m})\end{array}$ & $\begin{array}{c}\text { Densidade de } \\
\mathbf{d r e n a g e m} \\
\left(\mathbf{k m} / \mathbf{k m}^{\mathbf{2}}\right)\end{array}$ & $\begin{array}{c}\text { Declividade } \\
\mathbf{m e ́ d i a} \\
(\mathbf{m} / \mathbf{k m})\end{array}$ & $\begin{array}{c}\text { Precipitação } \\
\mathbf{m e ́ d i a} \\
(\mathbf{m m})\end{array}$ \\
\hline Córrego do Galo & 6,67 & 982 & 202,1 & $2.622,32$ & 2,67 & 15,77 & 1322,1 \\
\hline Fazenda Jucuruaba & 11,80 & 1693 & 281,4 & $4.413,21$ & 2,61 & 16,21 & 1384,9 \\
\hline Matilde & 2,95 & 211 & 84,6 & 770,32 & 3,65 & 15,73 & 1764,1 \\
\hline Pau D'alho & 2,78 & 302 & 112,5 & 719,44 & 2,38 & 18,11 & 1572,5 \\
\hline Iconha-Montante & 1,49 & 148 & 59,9 & 362,50 & 2,45 & 19,49 & 1564,3 \\
\hline Usina Fortaleza & 1,47 & 192 & 85,7 & 445,23 & 2,32 & 17,40 & 1378,3 \\
\hline Iúna & 3,41 & 405 & 101,5 & $1.106,68$ & 2,73 & 14,34 & 1361,2 \\
\hline Terra Corrida-Montante & 4,30 & 568 & 131,7 & $1.544,81$ & 2,72 & 14,40 & 1358,0 \\
\hline Itaici & 6,47 & 1015 & 174,1 & $2.617,35$ & 2,58 & 16,19 & 1371,7 \\
\hline Ibitirama & 2,72 & 337 & 110,1 & 997,62 & 2,96 & 17,46 & 1494,4 \\
\hline Rive & 14,52 & 2193 & 297,2 & 5809,93 & 2,65 & 16,17 & 1421,0 \\
\hline Castelo & 4,64 & 976 & 170,5 & $2.259,92$ & 2,32 & 18,29 & 1414,0 \\
\hline Usina São Miguel & 8,06 & 1458 & 227,1 & $3.388,60$ & 2,32 & 17,70 & 1473,2 \\
\hline Coutinho & 22,45 & 4576 & 405,5 & $11.519,78$ & 2,52 & 16,31 & 1446,1 \\
\hline
\end{tabular}

A análise de regressão simples permitiu a obtenção de funções regionais nas quais a área de drenagem foi utilizada como única variável independente. Para a definição de funções regionais a partir da análise de regressão múltipla, foram avaliadas 120 possíveis expressões, produzidas a partir do agrupamento das variáveis independentes consideradas (área de drenagem, perímetro, comprimento total de cursos d'água, densidade de drenagem, altitude média, declividade média e precipitação média de longo período). A partir da análise dos valores de coeficiente de correlação ajustado e da estatística de teste $\mathrm{C}_{\mathrm{p}}$, as funções selecionadas consideraram como variáveis independentes a área de drenagem, o comprimento total dos cursos d'água e a precipitação média de longo período. As funções matemáticas que envolveram adicionalmente o perímetro, a densidade de drenagem, altitude e/ou a declividade média não apresentaram previsões mais consistentes e exigiriam, quando da sua aplicação, um esforço substancialmente maior para a caracterização da bacia hidrográfica cuja vazão $\mathrm{Q}_{90}$ se desejasse avaliar.

Para a área de estudo, as melhores respostas foram obtidas com a definição de duas regiões hidrologicamente homogêneas. A primeira região (Região I) envolve as bacias hidrográficas dos rios Jucu, Benevente, Novo e Iconha, tendo sido definida a partir das vazões registradas nas estações de Córrego do Galo, Fazenda Jucuruaba, Matilde, Pau D'alho e Iconha-Montante. A segunda região (Região II), por sua vez, encerra a bacia hidrográfica do rio Itapemirim e foi definida a partir da análise das vazões registradas nas estações de Usina Fortaleza, Iúna, Terra Corrida-Montante, Itaici, Ibitirama, Rive, Castelo, Usina São Miguel e Coutinho. As funções regionais obtidas para cada região estão indicadas nas Tabelas 4 e 5 . Na Tabela 4, estão reunidas as funções regionais nas quais a área figura como variável independente; já na Tabela 5, estão apresentados os modelos nos quais a área de 
drenagem, o comprimento total dos cursos d'água e a precipitação média de longo período figuram como variáveis independentes.

Tabela 4: Funções regionais por região hidrológica homogênea considerando a área como variável independente

\begin{tabular}{|l|c|c|}
\hline \multicolumn{1}{|c|}{ Região hidrológica homogênea } & Função regional & Coeficiente de correlação \\
\hline Região I (Rios Jucu, Benevente, Novo e Iconha) & $\mathrm{Q}_{90}=0,0382 . \mathrm{A}^{0,76}$ & 0,96 \\
\hline Região II (Rio Itapemirim) & $\mathrm{Q}_{90}=0,0197 . \mathrm{A}^{0,84}$ & 0,97 \\
\hline
\end{tabular}

Nota: A representa a área de drenagem $\left(\mathrm{km}^{2}\right)$.

Tabela 5: Funções regionais por região hidrológica homogênea considerando a área, comprimento total de cursos d'água e precipitação média de longo período como variáveis independentes

\begin{tabular}{|l|c|c|}
\hline \multicolumn{1}{|c|}{ Região hidrológica homogênea } & Função regional & $\begin{array}{c}\text { Coeficiente de correlação } \\
\text { ajustado }\end{array}$ \\
\hline Região I (Rios Jucu, Benevente, Novo e Iconha) & $\mathrm{Q}_{90}=1,76 \cdot 10^{-7} \cdot \mathrm{A}^{0,43} \cdot \mathrm{C}^{0,48} \cdot \mathrm{P}^{1,49}$ & 0,99 \\
\hline Região II (Rio Itapemirim) & $\mathrm{Q}_{90}=7,81 \cdot \mathrm{A}^{-0,46} \cdot \mathrm{C}^{1,32} \cdot \mathrm{P}^{-1,03}$ & 0,99 \\
\hline
\end{tabular}

Nota: A representa a área de drenagem $\left(\mathrm{km}^{2}\right)$; C, o comprimento total de cursos d'água (km) e P, a precipitação média de longo período $(\mathrm{mm})$.

As Figuras 2 a 5 apresentam as respostas produzidas pela aplicação das expressões propostas para as duas regiões homogêneas citadas nesse estudo. As Figuras 2 e 3 apresentam os resultados referentes à aplicação da função regional na qual apenas a área figura como variável independente. As Figuras 4 e 5 ilustram os resultados obtidos a partir da função regional na qual área, comprimento total de cursos d'água e precipitação média de longo período figuram como variáveis independentes. Nas referidas figuras, a vazão real representa a vazão obtida a partir da análise probabilística dos registros de vazão de cada estação fluviométrica; a vazão estimada, por sua vez, corresponde à vazão obtida a partir da aplicação das funções regionais. Em todas as figuras, as barras de erro indicam variações de $30 \%$ em relação aos valores da vazão real.

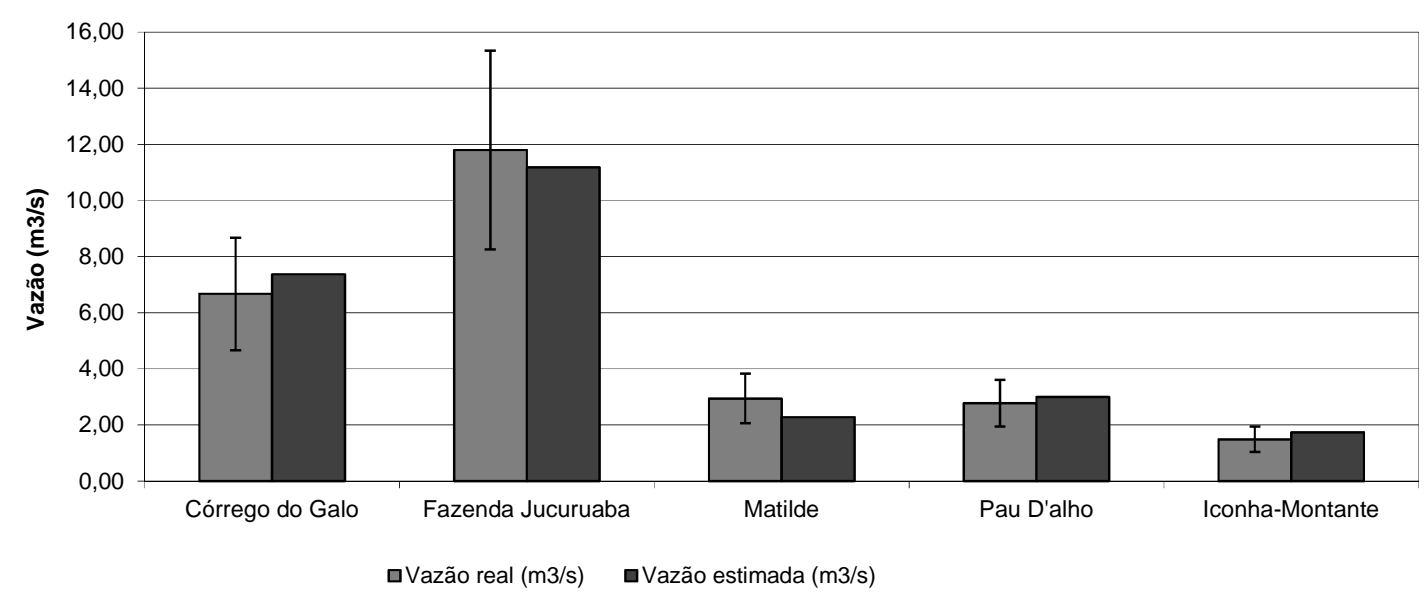

Figura 2: Vazões $Q_{90}$ reais e estimadas para a Região I, considerando a área como variável independente 


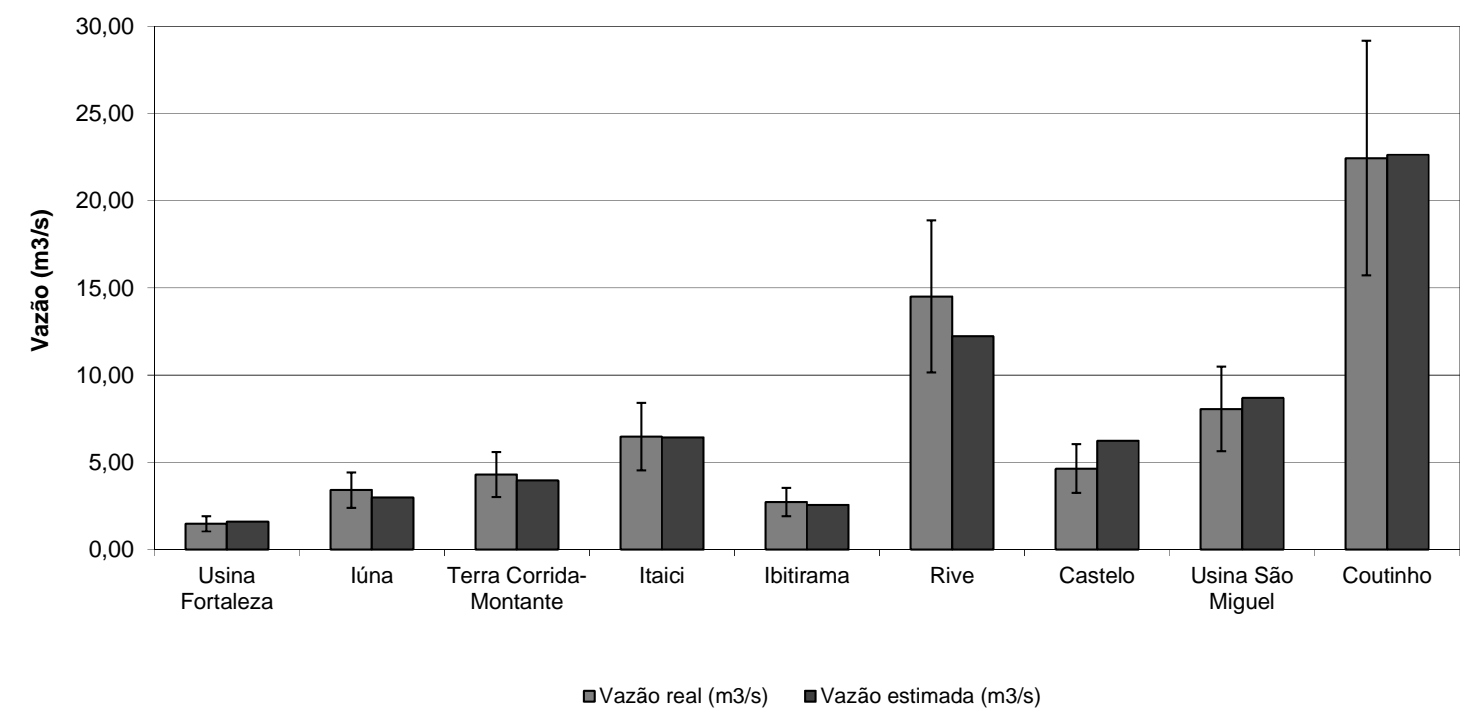

Figura 3: Vazões $Q_{90}$ reais e estimadas para a Região II, considerando a área como variável independente

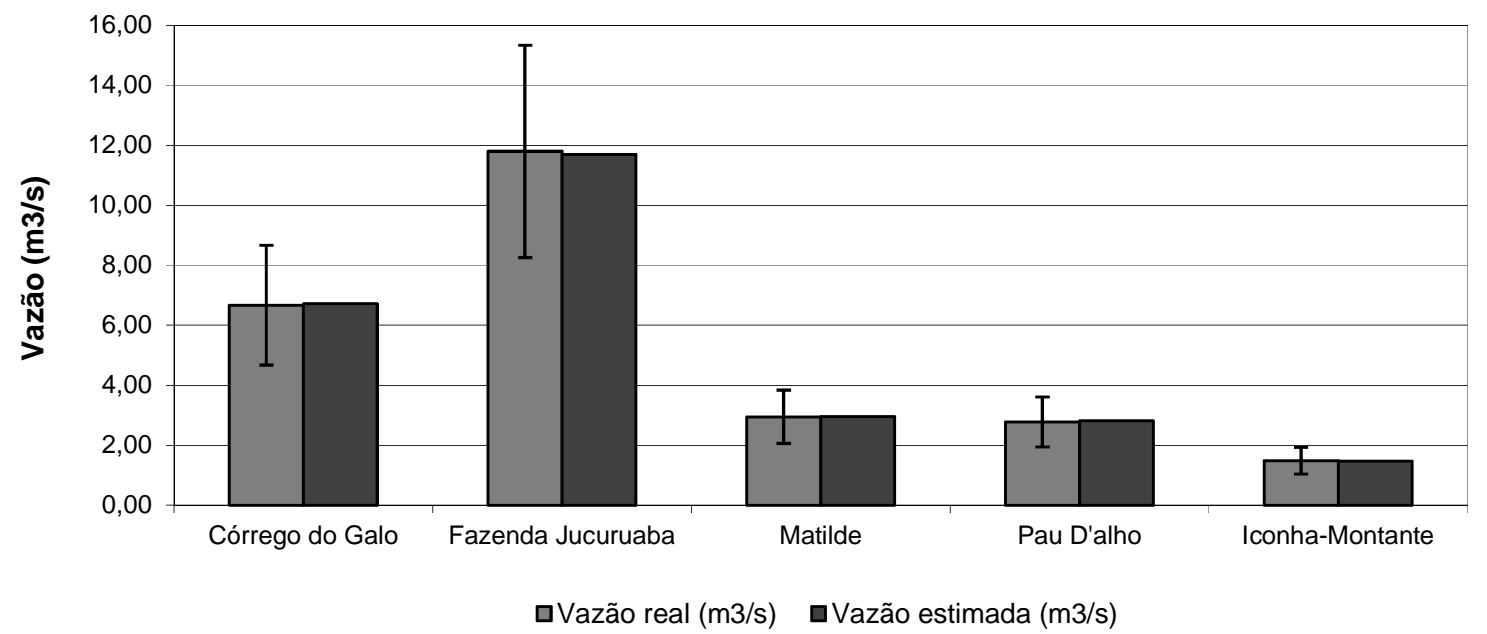

Figura 4: Vazões $Q_{90}$ reais e estimadas para a Região I, considerando área, comprimento total de cursos d'água e precipitação média de longo período como variáveis independentes

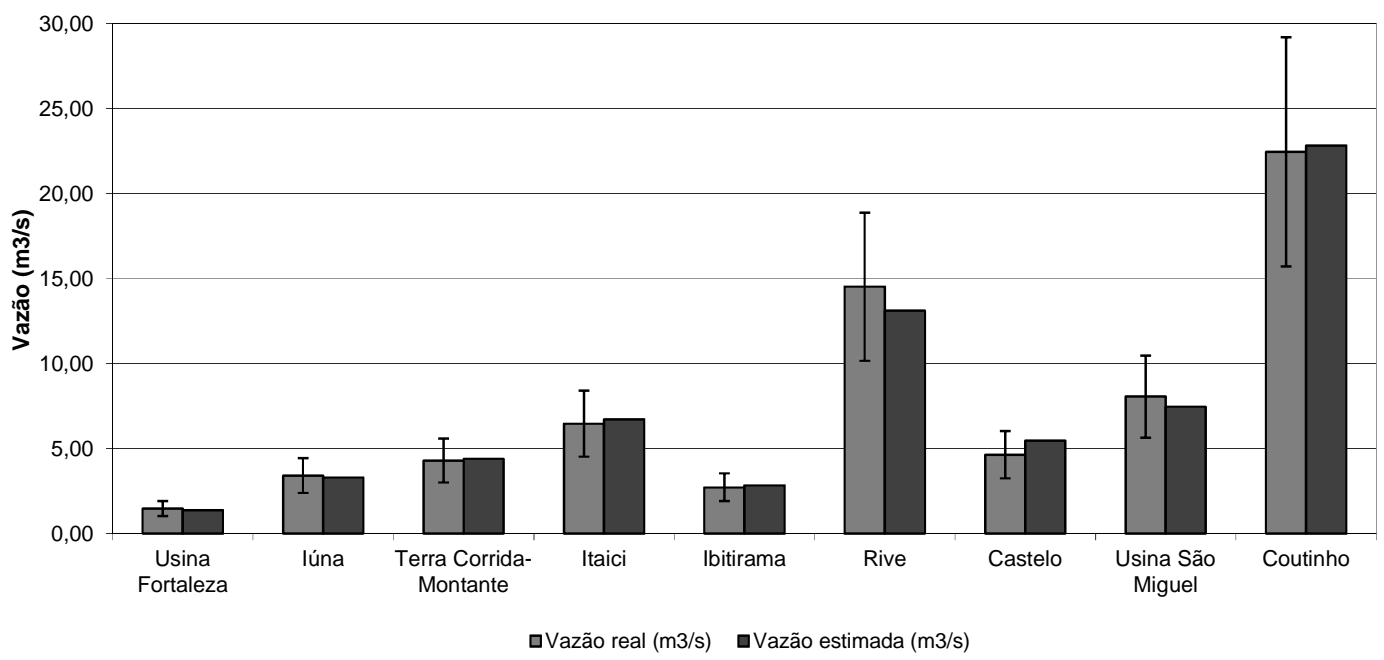

Figura 5: Vazões $\mathrm{Q}_{90}$ reais e estimadas para a Região II, considerando área, comprimento total de cursos d'água e precipitação média de longo período como variáveis independentes 
Os resultados obtidos, quando da aplicação das diferentes funções regionais estabelecidas, permitiram observar que as melhores estimativas para a vazão $\mathrm{Q}_{90}$ foram realizadas com o emprego das expressões obtidas a partir da regressão múltipla. Para as regiões I e II, os coeficientes de correlação ajustados associados à análise de regressão múltipla apresentaram-se superiores a 99\%, o que permitiu estimativas de vazões com erros inferiores a 5\%. Exceções foram observadas nas estações de Castelo (erro de 18\%), Rive (10\%) e Usina Fortaleza (7\%). Esses erros, no entanto, são inferiores a 30\%, limite considerado aceitável pela Eletrobrás (1985), quando da realização de estudos de regionalização de vazões.

É relevante observar, no entanto, que o esforço de caracterização fisiográfica e climatológica das bacias hidrográficas, quando da aplicação das funções regionais obtidas a partir da regressão múltipla, mostra-se substancialmente maior que aquele decorrente da aplicação de uma função regional que apresente apenas a área como variável independente.

\section{CONCLUSÕES}

A área de estudo foi dividida em duas regiões hidrologicamente homogêneas para apropriação da vazão $\mathrm{Q}_{90}$. A primeira região envolve as bacias hidrográficas dos rios Jucu, Benevente, Novo e Iconha. A segunda região encerra a bacia hidrográfica do Rio Itapemirim.

As melhores respostas obtidas para as estimativas da vazão $\mathrm{Q}_{90}$ envolveram funções regionais nas quais a área de drenagem, o comprimento total de cursos d'água e a precipitação média de longo período figuram como variáveis independentes. A aplicação das equações, no entanto, exige um cuidadoso trabalho de caracterização fisiográfica e do regime de precipitações das bacias hidrográficas de interesse.

\section{REFERÊNCIAS}

AGÊNCIA NACIONAL DE ÁGUAS (ANA). HIDRO sistema de informações hidrológicas - manual do usuário. Brasília: ANA/SIH, 2002.

BAENA, L. G. N. Regionalização de vazões para a bacia do rio Paraíba do Sul, a montante de Volta Redonda, a partir do modelo digital de elevação hidrologicamente consistente. 2002. Dissertação (Mestrado em Recursos Hídricos e Ambientais) - Universidade Federal de Viçosa, Viçosa, 2002.

CENTRAIS ELÉTRICAS DO BRASIL (Eletrobrás). Metodologia para a regionalização de vazões. Rio de Janeiro: Eletrobrás, 1985.

COSER, M. C. Regionalização de vazões $Q_{7,10}$ no estado do Espírito Santo. 2003. Dissertação (Mestrado em Engenharia Ambiental) - Universidade Federal do Espírito Santo, Vitória, 2003.

DINPASHOHA, Y. et al. Selection of variables for the purpose of regionalization of Iran's precipitation climate using multivariate methods. Journal of Hydrology, n. 297, p. 109-123, 2004.

ELESBON, A. A. A. Utilização de sistemas de informação geográfica na regionalização de vazões estudo de caso: bacias dos rios Mucuri, Itaúnas e São Mateus. 2004. Dissertação (Mestrado em Engenharia Ambiental) - Universidade Federal do Espírito Santo, Vitória, 2004. 
EUCLYDES, H. P. et al. Regionalização hidrológica na bacia do Alto São Francisco a montante da barragem de Três Marias, Minas Gerais. Revista Brasileira de Recursos Hídricos, v. 6, n. 2, p. 85-105, 2001.

FUNKE, R. Parameterization and regionalization of a runoff generation model for heterogeneous catchments. Phys. Chem. Earth, v. 24, n. 1-2, p. 49-54, 1999.

GONZÁLEZ, J.; VALDÉS, J. B. A regional monthly precipitation simulation model based on an Lmoment smoothed statistical regionalization approach. Journal of Hydrology, n. 348, p. 27-39, 2008.

LEVINE, D. M. et al. Estatística: teoria e aplicações. Rio de Janeiro: Livros Técnicos e Científicos, 2005.

MALLOWS, C. L. Some comments on Cp. Technometrics, v. 15, p. 661-75, 1973.

OBREGON, E.; TUCCI, C. E. M.; GOLDENFUM, J. A. Regionalização de vazões com base em séries históricas estendidas: bacias afluentes a Lagoa Mirim, RS. Revista Brasileira de Recursos Hídricos, v. 4, n. 1, p. 57-75, 1999.

REIS, J. A. T. et al. Regionalização de curvas de permanência de vazão para rios do estado do Espírito Santo. Revista Capixaba de Ciência e Tecnologia, n. 1, p. 28-35, 2006.

REIS, J. A. T. et al. Indicadores regionais aplicáveis à avaliação do regime de vazão dos cursos d'água da bacia hidrográfica do rio Itabapoana. Geociências, v. 27, n. 4, p. 509-516, 2008.

SANTHI, C. et al. Regional estimation of base flow for the conterminous United States by hydrologic landscape regions. Journal of Hydrology, n. 351, p. 139-153, 2008.

SEIBERT, J. Regionalization of parameters for a conceptual rainfall-runoff model. Agricultural and Forest Meteorology, n. 98-99, p. 279-293, 1999.

TIMILSENA, J.; PIECHOTA, T. Regionalization and reconstruction of snow water equivalent in the upper Colorado River basin. Journal of Hydrology, n. 352, p. 94-106, 2008.

TUCCI, C. E. M. Regionalização de vazões. Porto Alegre: ABRH, 2002.

WILTSHIRE, S. E. Grouping basins for regional flood frequency analysis. Hydrological Sciences Journal, n. 30, p. 151-159, 1985. 